\title{
Evidence for megalin-mediated proximal tubular uptake of L-FABP, a carrier of potentially nephrotoxic molecules
}

\author{
Yuko Oyama ${ }^{1}$, Tetsuro Takeda ${ }^{1,2}$, Hitomi Hama ${ }^{1}$, Atsuhito Tanuma ${ }^{1}$, Noriaki Iino ${ }^{1}$, \\ Kiyoko Sato ${ }^{1}$, Ryohei Kaseda ${ }^{1}$, Meilei $\mathrm{Ma}^{3}$, Tadashi Yamamoto ${ }^{3}$, Hiroshi Fujii ${ }^{4}$, \\ Junichiro J Kazama ${ }^{5}$, Shoji Odani ${ }^{6}$, Yoshio Terada ${ }^{7}, K_{\text {Kunihiro Mizuta }}{ }^{8}$, \\ Fumitake Gejyo ${ }^{1}$ and Akihiko Saito ${ }^{1,2}$
}

${ }^{1}$ Division of Clinical Nephrology and Rheumatology, Niigata University Graduate School of Medical and Dental Sciences, Niigata, Japan; ${ }^{2}$ Department of Applied Molecular Medicine, Niigata University Graduate School of Medical and Dental Sciences, Niigata, Japan; ${ }^{3}$ Department of Structural Pathology, Institute of Nephrology, Niigata University Graduate School of Medical and Dental Sciences, Niigata, Japan; ${ }^{4}$ Division of Molecular and Cellular Biology, Niigata University Graduate School of Medical and Dental Sciences, Niigata, Japan; ${ }^{5}$ Division of Intensive Care Medicine, Niigata University Hospital, Niigata, Japan; ${ }^{6}$ Department of Biology, Faculty of Science, Niigata University, Niigata, Japan; ${ }^{7}$ Department of Homeostasis Medicine and Nephrology, Graduate School, Tokyo Medical and Dental University, Tokyo, Japan and ${ }^{8}$ Department of Otolaryngology, Hamamatsu University School of Medicine, Hamamatsu, Japan

\begin{abstract}
Liver-type fatty acid binding protein (L-FABP) binds with high affinity to hydrophobic molecules including free fatty acid, bile acid and bilirubin, which are potentially nephrotoxic, and is involved in their metabolism mainly in hepatocytes. L-FABP is released into the circulation, and patients with liver damage have an elevated plasma L-FABP level. L-FABP is also present in renal tubules; however, the precise localization of L-FABP and its potential role in the renal tubules are not known. In this study, we examined the cellular and subcellular localization of L-FABP in the rat kidney and tried to determine from where the L-FABP in kidney tissues had originated. Immunohistochemical studies of kidney sections localized L-FABP in the lysosomes of proximal tubule cells (PTC). In rats with carbon tetrachloride $\left(\mathrm{CCl}_{4}\right)$-induced acute liver injury, we detected high levels of L-FABP in the circulation and in the kidney compared with those in the control rat by immunoblotting, while reverse transcription-polymerase chain reaction showed that the level of L-FABP mRNA expression in the kidney of $\mathrm{CCl}_{4}$-treated rats was low and did not differ from that in the control rat. When ${ }^{35} \mathrm{~S}-\mathrm{L}-\mathrm{FABP}$ was intravenously administered to rats, the kidneys took up ${ }^{35}$ S-L-FABP more preferentially than the liver and heart, and histoautoradiography of kidney sections revealed that ${ }^{35}$ S-L-FABP was internalized via the apical domains of PTC. Quartz-crystal microbalance analysis revealed that L-FABP bound to megalin, a multiligand endocytotic receptor on $\mathrm{PTC}$, in a $\mathrm{Ca}^{2+}$-dependent manner. Degradation assays using megalin-expressing rat yolk sac tumor-derived L2 cells demonstrated that megalin mediated the cellular uptake and catabolism of ${ }^{125} \mathrm{I}-\mathrm{L}-\mathrm{FABP}$. In conclusion, circulatory L-FABP was found to be filtered by glomeruli and internalized by PTC probably via megalin-mediated endocytosis. These results suggest a novel renal uptake pathway for L-FABP, a carrier of hydrophobic molecules, some of which may exert nephrotoxic effects.
\end{abstract}

Laboratory Investigation (2005) 85, 522-531, advance online publication, 31 January 2005; doi:10.1038/labinvest.3700240

Keywords: endocytosis; liver-type fatty acid binding protein; lysosome; megalin; nephrotoxicity; proximal tubule cell

Correspondence: Dr A Saito, MD, PhD, Department of Applied Molecular Medicine, Niigata University Graduate School of Medical and Dental Sciences, 1-757 Asahimachi-dori, Niigata 951-8510, Japan.

E-mail: akisaito@med.niigata-u.ac.jp

Received 30 June 2004; revised 2 December 2004; accepted 4 December 2004; published online 31 January 2005
Fatty acid binding proteins (FABPs) are a family of 14-15-kDa proteins that play an important role in the intracellular metabolism of long-chain free fatty acids (FFA). They are involved in the transport of FFA from the plasma membrane to sites for oxidation (mitochondria, peroxisomes), sites for esterification into triacylglycerols or phospholipids, and 
the nucleus for gene regulation. ${ }^{1}$ To date, nine types of FABPs have been identified and are named according to the tissue in which they were first identified.

Liver-type FABP (L-FABP), which is mainly found in hepatocytes, is thought to play a role in hepatic metabolism of FFA. L-FABP was also shown to bind with other hydrophobic molecules such as lysophospholipids, ${ }^{2}$ eicosanoids, ${ }^{3,4}$ bile acids, ${ }^{5}$ bilirubin, ${ }^{6}$ heme, $^{7}$ carcinogenic agents ${ }^{8}$ and hypolipidemic drugs. ${ }^{9}$ When L-FABP was purified from the liver or intestine of rats, it was bound to endogenous ligands with high affinity and only dissociated from them under stringent hydrophobic conditions. ${ }^{10,11}$ L-FABP is present in the circulation in healthy individuals, ${ }^{12}$ and it likely acts as a circulatory carrier of various ligands. Patients with liver damage have an elevated serum L-FABP level ${ }^{12}$ as well as elevated serum levels of bilirubin, bile acids and other metabolites. This suggests that L-FABP may play a pathological role by transporting increased amounts of ligands to other tissues.

It was reported that L-FABP was localized in the proximal tubule cells (PTC) of the human kidney. ${ }^{13}$ However, in the rat kidney, L-FABP was detected not only in PTC but also in distal tubule cells (DTC). ${ }^{14}$ Moreover, the precise subcellular localization of L-FABP in the kidney, and the origin and functions of renal L-FABP are not known. L-FABP is putatively involved in the renal metabolism of FFA, which are major substrates for oxidation in the renal cortex $^{15-17}$ but have harmful effects on the kidney in nephrotic conditions. ${ }^{18}$

In this study, we determined the cellular and subcellular localization of L-FABP in the rat kidney by immunohistochemical analyses. We also provide evidence that the kidney does not synthesize a significant amount of L-FABP, but that L-FABP accumulates in PTC through reabsorption from glomerular filtrates and that this reabsorption is likely mediated by megalin, a multiligand endocytotic receptor. ${ }^{19}$ The significance of the novel renal uptake pathway for L-FABP is discussed.

\section{Materials and methods}

\section{Antibodies}

Rabbit antisera were raised against rat L-FABP as described previously. ${ }^{20}$ Anti-rat megalin IgG antibody was prepared as described previously. ${ }^{21}$ Crossadsorbed horseradish peroxidase (HRP)-conjugated goat anti-rabbit IgG antibody $(3 \mu \mathrm{g} / \mathrm{ml})$ was purchased from DAKO (Glostrup, Denmark). Goat antirabbit IgG antibody conjugated with $10 \mathrm{~nm}$ gold particles $(30 \mu \mathrm{g} / \mathrm{ml})$ was purchased from BBInternational (Cardiff, UK). Monoclonal anti-bovine serum albumin (BSA) IgG was obtained from Biogenensis (Poole, Dorset, UK).

\section{Animals}

Male Sprague-Dawley rats (Charles River, Yokohama, Japan) weighing 150-200 g, were used in the experiments. They were given free access to food and water, and were maintained under normal laboratory conditions. All animals were handled following ethical procedures according to the Guidelines for Animal Experimentation of Niigata University.

\section{Immunohistochemistry and Immunoelectron Microscopy}

Normal rats were anesthetized by inhalation of diethyl ether, and the kidneys and liver were excised. For immunohistochemistry, the kidneys and liver tissues were placed in Tissue-Tek ${ }^{\circledR}$ O.C.T. Compound (Sakura Finetechnical Co., Ltd, Tokyo, Japan) and frozen in dry ice-acetone. Cryosections of $5 \mu \mathrm{m}$ thickness were treated with methanol containing $3 \% \mathrm{H}_{2} \mathrm{O}_{2}$ to block endogenous peroxidase activity. After washing in PBS, sections were incubated sequentially with anti-L-FABP serum (1:2000) for $2 \mathrm{~h}$ and HRP-conjugated anti-rabbit IgG antibody (1:200) for $30 \mathrm{~min}$, and then subjected to immunodetection with a $3,3^{\prime}$-diaminobenzidine substrate kit (DAKO) and counterstaining with methyl green. The sections were examined by light microscopy. For immunoelectron microscopy, kidneys were cut into cubes $\left(5 \times 5 \times 5 \mathrm{~mm}^{3}\right)$, fixed in $4 \%$ paraformaldehyde for $2 \mathrm{~h}$, dehydrated in graded ethanol, and embedded in LR white resin (ProSci Tech, Townsville, Australia). Ultrathin sections were cut and placed on nickel grids. The grids were incubated at $4{ }^{\circ} \mathrm{C}$ with anti-L-FABP serum (1:5000) overnight, and then with $10 \mathrm{~nm}$ gold-conjugated anti-rabbit IgG antibody (1:100) for $1 \mathrm{~h} .{ }^{22}$ Sections were stained with lead citrate, coated with carbon, and examined under an electron microscope (HITACHI H-7100, Tokyo, Japan).

\section{Induction of Liver Injury in Rats}

To induce acute liver injury, male rats were treated with carbon tetrachloride $\left(\mathrm{CCl}_{4}\right)$ (Wako Pure Chemical Industries, Ltd, Osaka, Japan). ${ }^{23} \mathrm{CCl}_{4}(99.8 \%)$ was diluted with olive oil and injected at a dose of 0.2 or $1 \mathrm{ml} \mathrm{CCl}_{4} / \mathrm{kg}$ body weight (final injected volume: $2 \mathrm{ml} / \mathrm{kg}$ body weight ${ }^{24}$ intraperitoneally. The same volume of olive oil alone was injected intraperitoneally in control rats. At $24 \mathrm{~h}$ after administration, rats were anesthetized by inhalation of isoflurane. Blood samples were obtained from the abdominal aorta, and centrifuged at $1500 \mathrm{~g}$ at $4^{\circ} \mathrm{C}$ for $15 \mathrm{~min}$ for serum separation. After the rats were killed by systemic perfusion of $0.9 \%$ saline, the kidneys and liver were excised for the following experiments. 


\section{Immunoblotting}

One-half of the left kidney was homogenized in lysis buffer (1\% Triton X-100, 20 mM HEPES, pH 7.0; $150 \mathrm{mM} \mathrm{NaCl}, 1 \mathrm{mM}$ EDTA, $1 \mathrm{mM}$ PMSF, and $1 \mathrm{mM}$ leupeptin) and centrifuged at $15000 \mathrm{~g}$ at $4{ }^{\circ} \mathrm{C}$ for 30 min. The protein concentration was determined using a bicinchoninic acid protein assay kit (Pierce Chemicals Co., Rockford, IL, USA). The tissue lysate and serum samples were subjected to $15 \%$ sodium dodecyl sulfate-polyacrylamide gel electrophoresis under nonreducing conditions and electrophoretically blotted onto Immun-Blot polyvinylidine difluoride membranes (Bio-Rad Laboratories, Hercules, CA, USA). Membranes were blocked in a buffer containing Tris-HCl, pH 7.4, $137 \mathrm{mM} \mathrm{NaCl,}$ $2.7 \mathrm{mM} \mathrm{KCl}$, and $5 \%$ fetal calf serum (FCS) (Invitrogen Corp., Carlsbad, CA, USA), incubated with anti-L-FABP serum (1:500) for $2 \mathrm{~h}$, incubated with HRP-conjugated anti-rabbit IgG antibody (1:1000) for $1 \mathrm{~h}$, and visualized using enhanced chemiluminescence (Supersignal ${ }^{\circledR}$ ) (Pierce Chemicals Co.).

\section{Reverse Transcription-Polymerase Chain Reaction (RT-PCR)}

Total RNA was extracted from the other half of the left kidney of the $\mathrm{CCl}_{4}$-treated rats and from the liver of control rats by the standard method using Isogen ${ }^{\mathbb{R}}$ (NIPPONGENE, Tokyo, Japan). An equal amount (5 $\mu \mathrm{g}$ ) of total RNA from these tissues was reversetranscribed using a Superscript First-strand Synthesis system (Invitrogen Corp.). The cDNA samples were amplified by PCR using specific primers for rat L-FABP cDNA (sense, 5'-CTGAGGACCTCATCCA GAA; antisense, 5'-CACCCTCCATCTTAACCAC; product size, $189 \mathrm{bp}$ ), or glyceraldehyde-3-phosphate dehydrogenase (GAPDH) cDNA as an internal control (sense, 5'-TGCATCCTGCACCACCAACT; antisense, 5'-CGCCTGCTTCACCACCTTC; product size, $349 \mathrm{bp})$. PCR amplification was performed with 30 cycles of $95^{\circ} \mathrm{C}$ for $30 \mathrm{~s}, 50^{\circ} \mathrm{C}$ for $30 \mathrm{~s}$, and $72^{\circ} \mathrm{C}$ for $30 \mathrm{~s}$.

\section{Preparation of Rat L-FABP cDNA in the pGEM-T Vector}

RT-PCR was performed to amplify the entire rat L-FABP cDNA using total RNA that had been extracted from the liver of normal rats. The sense and antisense primers were synthesized based on the nucleotide sequences ${ }^{25}$ of the $5^{\prime}$ portion (nucleotides 1-20) and $3^{\prime}$ portion (nucleotides 413-432) of rat L-FABP cDNA. The 432-bp PCR product was subcloned into the pGEM-T vector (Promega, Madison, WI, USA). The fidelity of the PCR product was confirmed by automated sequencing.

\section{Preparation and Radioiodination of Recombinant Rat L-FABP}

The cDNA encoding rat L-FABP was amplified by PCR using the clone in the pGEM-T vector as the template, and inserted into the pGEX-6p-1 vector (Amersham Biosciences, Piscataway, NJ, USA). The fidelity of the PCR products was confirmed by automated sequencing. Glutathione $S$-transferase (GST) fusion protein containing rat L-FABP was expressed in Escherichia coli DH5 $\alpha$ (Takara, Kyoto, Japan), and purified using the Bulk Purification Module for GST fusion proteins (Amersham Biosciences) according to the manufacturer's instructions. GST was completely cleaved from L-FABP using PreScission Protease ${ }^{\mathbb{R}}$ (Amersham Biosciences). The recombinant rat L-FABP $(100 \mu \mathrm{g})$ was radiolabeled using $1 \mathrm{mCi} \mathrm{Na}^{125} \mathrm{I}$ (Amersham Biosciences) and one Iodo-Bead (Pierce Chemicals Co.) according to the manufacturers' instructions. The specific activity of ${ }^{125} \mathrm{I}-\mathrm{L}-\mathrm{FABP}$ was 830 c.p.m./ng.

\section{Administration of ${ }^{125} \mathrm{I}-\mathrm{L}-\mathrm{FABP}$ to Rats and Organ Uptake of ${ }^{125} \mathrm{I}-\mathrm{L}-\mathrm{FABP}$}

Rats received a single intravenous injection of ${ }^{125} \mathrm{I}-\mathrm{L}$ FABP $(0.5 \mu \mathrm{g}$ in $1.5 \mathrm{ml}$ PBS) through the left femoral vein or tail vein. At the indicated time points, the kidneys, liver and heart were perfused with $0.9 \%$ saline through the left ventricle and excised. The uptake of ${ }^{125} \mathrm{I}-\mathrm{L}-\mathrm{FABP}$ by these tissues was quantified by gamma counting and expressed as c.p.m. per weight of tissue.

\section{Histoautoradiography for ${ }^{35}$ S-L-FABP Uptake in Kidney Sections}

${ }^{35}$ S-labeled rat L-FABP was produced by mixing $600 \mu \mathrm{l}$ of TNT SP6 rabbit reticulocyte Quick Coupled Transcription/Translation system (Promega) with $15 \mu$ l of Redivu ${ }^{35}$ S-methionine (370 MBq/ml) (Amersham Biosciences) and $15 \mu \mathrm{g}$ of the pGEM-T clone containing the rat L-FABP cDNA sequence according to the manufacturer's instructions. The in vitro translation products were purified by dialyzing out nonincorporated ${ }^{35} \mathrm{~S}$-methionine. A volume of $50 \mu \mathrm{l}$ of the product was injected into the tail vein of a rat. After $10 \mathrm{~min}$, the rat was killed by systemic perfusion of $0.9 \%$ saline and the kidneys and liver were excised. A part of each tissue was frozen in dry iceacetone. Labeled cryosections $(10 \mu \mathrm{m})$ of the kidneys and liver were placed on a phosphor-imaging plate for $12 \mathrm{~h}$. The exposed imaging plate was scanned and quantified with a Bio-Imaging analyzer (BAS 5000, Fujifilm, Tokyo, Japan) under the following specific reading conditions: gradation, 256; resolution, 100; sensitivity, 10 000; latitude, 5. The rest of the kidney was cut into axial sections, immersed in $4 \%$ paraformaldehyde, dehydrated with graded ethanol and embedded in paraffin. Paraffin sections were cut at a thickness of $7 \mu \mathrm{m}$, dipped in photographic emulsion NTB2 (Eastman Kodak Company, Rochester, NY, USA) and exposed in the dark at $4^{\circ} \mathrm{C}$ for 12 days. Slides were developed with developer 
D-19 (Eastman Kodak) and stained with hematoxylin and eosin.

\section{Quartz-Crystal Microbalance (QCM)}

The binding of L-FABP to megalin was examined using a highly sensitive $27 \mathrm{MHz}$ QCM (Affinix Q) (Initium, Tokyo, Japan) as described previously. ${ }^{26}$ Briefly, the QCM sensor chips were activated by a 1:1 mixture of $100 \mathrm{mg} / \mathrm{ml}$ 1-(3-dimethylaminopropyl)-3 ethylcarbodiimide hydrochloride (EDC) (Sigma-Aldrich, St Louis, MO, USA) and $100 \mathrm{mg} / \mathrm{ml} N$ hydroxysuccinimide (NHS) (Wako Pure Chemical Industries, Ltd) in water. Rat megalin, which had been prepared from renal microvillar membranes by immunoaffinity chromatography as previously described, ${ }^{27}$ at a concentration of $10 \mu \mathrm{g} / \mathrm{ml}$ in buffer B (10 mM HEPES, pH 7.4, $150 \mathrm{mM} \mathrm{NaCl,} 2 \mathrm{mM} \mathrm{CaCl}_{2}$ ), or fatty acid (FA)-free BSA (Sigma-Aldrich) in the negative control experiment, was immobilized on the sensor chips. The sensor chips were soaked at $23^{\circ} \mathrm{C}$ in $8 \mathrm{ml}$ of buffer B or C (10 mM HEPES, pH 7.4; $150 \mathrm{mM} \mathrm{NaCl}, 10 \mathrm{mM}$ EDTA) in the incubation chamber. Recombinant L-FABP $(1 \mu \mathrm{g} / \mathrm{ml})$, or BSA (fraction V, Sigma-Aldrich) $(1 \mu \mathrm{g} / \mathrm{ml})$ in the negative control experiment, was added into the chamber for binding to megalin. Bovine lactoferrin (Sigma-Aldrich), a ligand for megalin, ${ }^{28}$ was used for competition of L-FABP binding to megalin. Lactoferrin ( $3 \mu \mathrm{g} /$ $\mathrm{ml}$ ) was added to the chamber and after it reached the steady state of its binding to megalin, L-FABP $(1 \mu \mathrm{g} / \mathrm{ml})$ was injected into the chamber for binding to megalin. The QCM experiments were repeated at least three times. The resonance frequency of the QCM was defined as the 0 position after equilibrium. The stability and drift of the $27 \mathrm{MHz}$ QCM frequency in the solution were $\pm 3 \mathrm{~Hz}$. The binding affinity was determined from the frequency changes upon cumulative injection of a small volume $(8 \mu \mathrm{l})$ of $1 \mu \mathrm{g} / \mathrm{ml}$ L-FABP as previously described. ${ }^{26}$

\section{Cellular Uptake and Degradation of ${ }^{125}$ I-L-FABP}

Megalin-expressing rat yolk sac tumor-derived L2 cells $^{29}$ were grown $\left(37^{\circ} \mathrm{C}, 5 \% \mathrm{CO}_{2}\right)$ to confluence $\left(1 \times 10^{5}\right.$ cells/well $)$ in Dulbecco's modified Eagle's medium (DMEM) (Invitrogen Corp.) supplemented with $10 \%$ FCS in 12-well tissue culture plates coated with $1 \%$ gelatin. The cells were washed with DMEM and incubated in DMEM containing $0.1 \%$ BSA with ${ }^{125} \mathrm{I}-\mathrm{L}-\mathrm{FABP}(1.0 \mu \mathrm{g} / \mathrm{ml})$ in the absence or presence of a competitor for $2 \mathrm{~h}$. A GST fusion protein containing receptor-associated protein (RAP), a specific inhibitor of ligand binding to megalin, was prepared as described previously ${ }^{30}$ and used as a competitor. Then, the culture media were collected and precipitated with 15\% trichloroacetic acid (TCA), and the radioactivity levels of the TCA-soluble degradation products were quantified by gamma counting. To correct for liberation of iodine from ${ }^{125}$ I-labeled ligands, the level of TCAsoluble radioactivity of medium that had been incubated for $2 \mathrm{~h}$ in the absence of L2 cells, was subtracted from that found in the samples. Statistical analyses were carried out using the unpaired Student's $t$-test. $P$-values $<0.01$ were considered to be statistically significant.

\section{Results}

\section{L-FABP is Localized in the Lysosomes of Rat PTC}

There was a discrepancy in previous studies on the localization of L-FABP in the mammalian kidney in that L-FABP was localized in PTC and DTC in the rat kidney, ${ }^{14}$ but only in PTC in the human kidney. ${ }^{13} \mathrm{We}$ performed immunohistochemical analyses for the distribution of L-FABP in the rat kidney. We studied the distribution both by light microscopy of cryosections and at the subcellular level by immunoelectron microscopy of ultrathin sections. L-FABP was detected in PTC in the cortex, whereas no obvious immunoreaction was observed in the medulla (Figure 1a). At higher magnification, L-FABP showed a granular staining pattern in PTC, but negligible staining in the glomeruli and DTC (Figure 1b). On immunoelectron microscopy, L-FABP staining was predominantly observed in the lysosomes of PTC (Figure 1c). These results suggested either of two possibilities: (1) L-FABP is taken up by PTC from glomerular filtrates via receptor-mediated endocytosis, or (2) L-FABP is synthesized in PTC and is transported to the lysosomes.

\section{Renal L-FABP Synthesis is Very Low and There may be a Pathway to Transport L-FABP to the Kidney via the Circulation}

L-FABP is abundantly expressed in hepatocytes and is released into the circulation. ${ }^{12}$ To investigate the possibilities mentioned above, we performed experiments using a well-established rat model of acute liver injury that was induced by intraperitoneal injection of $\mathrm{CCl}_{4} \cdot{ }^{23}$ The $\mathrm{CCl}_{4}$-treated rats had an elevated serum level of alanine aminotransferase, which had possibly been released from damaged hepatocytes; however, they did not have elevated levels of blood urea nitrogen nor creatinine, which are renal injury markers (data not shown). Immunoblotting revealed that the $\mathrm{CCl}_{4}$-treated rats had elevated levels of L-FABP in the serum and in the kidney compared with the control rat (Figure 2a). We performed immunohistochemical staining of LFABP in kidney sections of $\mathrm{CCl}_{4}$-treated and control rats, and compared the distribution of L-FABP. We observed that the increased level of L-FABP in the kidney of $\mathrm{CCl}_{4}$-treated rats that had been found on immunoblotting, was solely due to the accumulation of L-FABP in PTC (data not shown). The mRNA expression of L-FABP in the kidney and liver was 

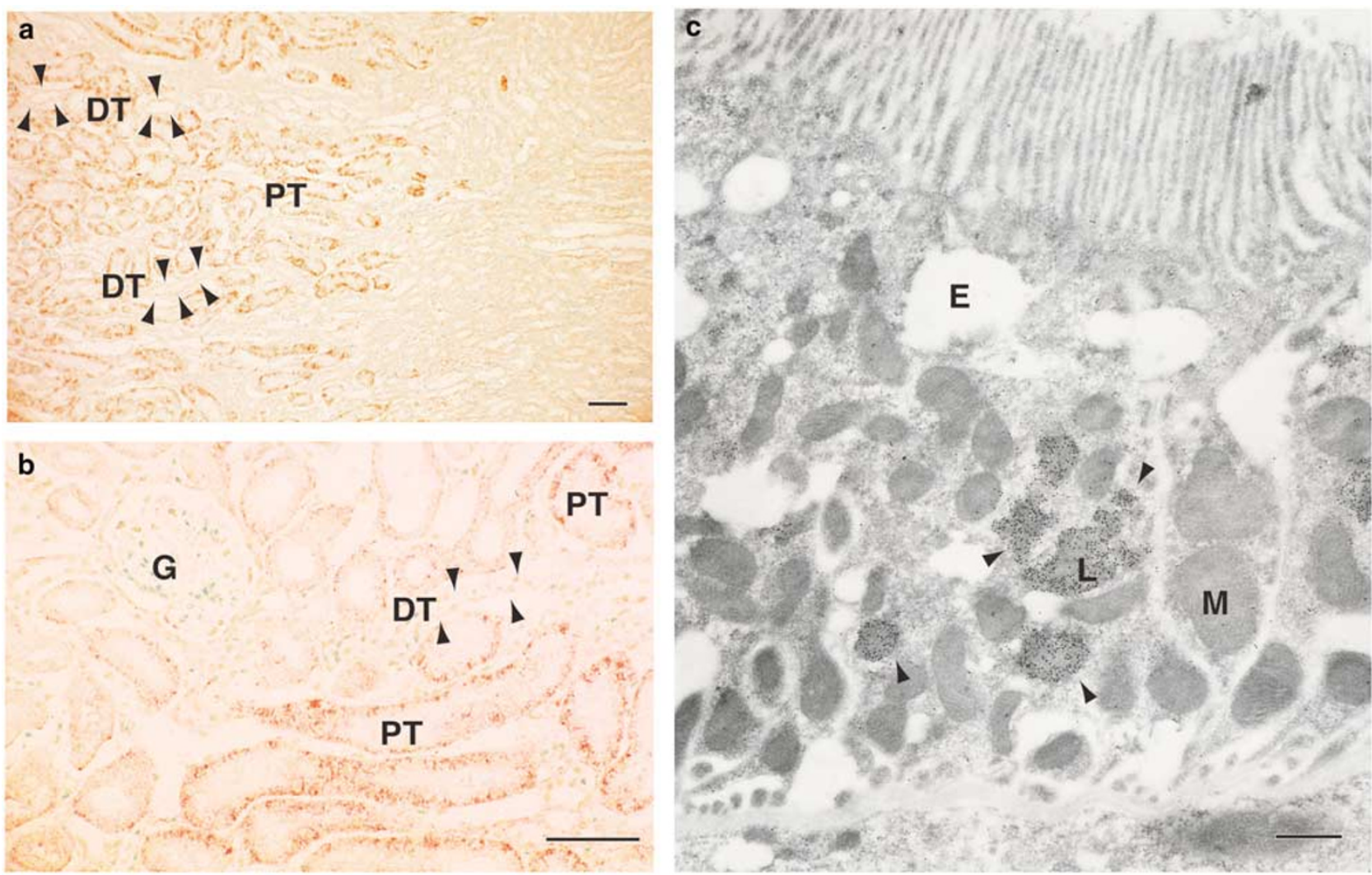

Figure 1 Immunohistochemical analyses of cellular and subcellular localization of L-FABP in the normal rat kidney. Kidney sections were incubated with anti-L-FABP serum. (a) Low-magnification immunomicroscopy shows that L-FABP is present in the proximal tubules (PT), but not in the distal tubules (DT) (arrowheads), in the cortex. (b) At high magnification, granular immunostaining in the PT is observed, while the glomeruli (G) and the DT (arrowheads) are negative for L-FABP. (c) Immunoelectron microscopy of ultrathin sections of proximal tubules. L-FABP is localized in the lysosomes (arrowheads) of the proximal tubule cells. Mitochondria and endosomes are negative for L-FABP. E, endosome; L, lysosome; M, mitochondrion. Scale bars: $100 \mu \mathrm{m}$ in (a) $500 \mu \mathrm{m}$ in (b) $1 \mu \mathrm{m}$ in (c).

analyzed by RT-PCR. In the control rats, there was a very low level of mRNA expression of L-FABP in the kidney compared with that in the liver. The finding is compatible with a previous report on the low mRNA expression of L-FABP both in the human and rat kidney. ${ }^{14}$ In rats that had been treated with different doses of $\mathrm{CCl}_{4}$, the level of L-FABP mRNA expression in the kidney was low and did not differ from that in the kidney of control rats (Figure 2b). These results suggest that renal L-FABP synthesis is very low and that there may be a pathway to transport L-FABP to the kidney via the circulation.

\section{Circulatory L-FABP is Filtered by the Glomeruli and Reabsorbed by PTC}

To examine whether circulatory L-FABP is taken up by the kidneys preferentially over other tissues, we carried out a radiolabeled tracer uptake assay. After ${ }^{125} \mathrm{I}-\mathrm{L}-\mathrm{FABP}$ was intravenously administered to rats, the kidneys, liver, and heart were removed and their radioactivity was measured (Figure 3). Among the examined tissues, the highest level of radioactivity was observed in the kidney at all time points examined. To determine the site and the mechanism of renal uptake of circulatory L-FABP, we intravenously administered ${ }^{35} \mathrm{~S}-\mathrm{L}-\mathrm{FABP}$ and then performed histoautoradiography of rat kidney and liver sections. On phosphor-imaging plates, radioactivity was detected in the renal cortex (Figure 4a), but not in the liver (Figure 4b). The silver grains exclusively accumulated in structures histologically suggested to be proximal convoluted tubules (Figure 4c). There was no significant uptake of ${ }^{35} \mathrm{~S}$-L-FABP by the glomeruli, vasculature, the outer stripe nor medullary region of the kidney. At higher magnification, we observed that the silver grains predominantly accumulated in the apical domains of PTC (Figure 4d), confirming that L-FABP in the glomerular filtrate is taken up by PTC.

\section{L-FABP Directly Binds to Megalin in a $\mathrm{Ca}^{2+}$-Dependent Manner}

The reabsorption of a variety of proteins from the glomerular filtrate by PTC is mediated by megalin, a cell membrane endocytotic receptor. To study whether megalin has the potential of mediating the 
a

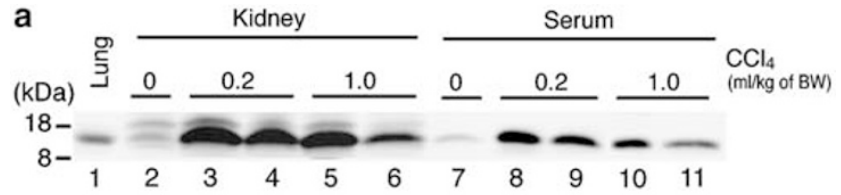

b

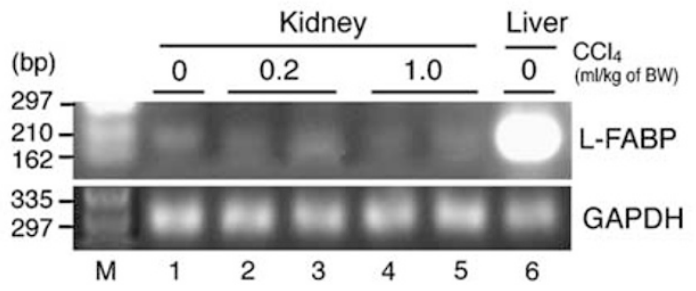

Figure 2 Immunoblotting and RT-PCR analyses for L-FABP in the kidneys of $\mathrm{CCl}_{4}$-treated rats. Rats were intraperitoneally administered $0,0.2$ or $1.0 \mathrm{ml} / \mathrm{kg} \mathrm{CCl}{ }_{4}$ in olive oil to induce acute liver injury. (a) Immunoblotting detected L-FABP as a $\sim 15 \mathrm{kDa}$ band in the lysate of the lungs of a normal rat (lane 1). The levels of LFABP in the kidneys (lanes 3-6) and serum (lanes 8-11) of $\mathrm{CCl}_{4}$ treated rats were markedly higher than those in the kidney (lane 2) and sera (lane 7) of a non-CCl $\mathrm{Cl}_{4}$-treated rat. The amounts of loaded proteins are as follows: lane 1, lung $10 \mu \mathrm{g}$; lanes 2-6, kidney $100 \mu \mathrm{g}$; lanes 7-11, serum $100 \mu \mathrm{g}$. (b) RT-PCR analysis for L-FABP mRNA and GAPDH mRNA expression showed that LFABP mRNA expression was very low in the control kidney (lane 1) compared with that in the control liver (lane 6), and that the level of L-FABP mRNA expression in the kidneys of the $\mathrm{CCl}_{4}$ treated rats (lanes 2-5) did not differ from that in the control kidney (lane 1). M, DNA marker.

absorption of L-FABP, immuno-affinity-purified rat megalin was assayed for L-FABP binding activity by QCM analysis. L-FABP bound to megalin in a $\mathrm{Ca}^{2+}$. dependent manner (Figure 5a, b), but it did not bind to FA-free BSA even in the presence of $\mathrm{Ca}^{2+}$ (Figure 5c). BSA (FA-bound) did not bind to megalin even in the presence of $\mathrm{Ca}^{2+}$ (Figure 5d). When lactoferrin, a ligand for megalin, ${ }^{28}$ was initially injected and allowed to reach the steady state of its binding to megalin before injection of L-FABP, the binding of L-FABP to megalin was completely inhibited (Figure 5d). In binding affinity analysis, the maximum binding quantity and the equilibrium dissociation constant for the binding of L-FABP to megalin were $(1.26 \pm 0.31) \times 10^{2} \mathrm{~Hz}$ and $0.11 \pm 0.07 \mu \mathrm{mol} / \mathrm{l}$ (mean \pm s.d., $n=3$ ), respectively.

\section{Cellular Uptake and Degradation of L-FABP are Mediated by Megalin}

The ability of megalin to mediate the cellular uptake and catabolism of L-FABP was examined in L2 cells, a rat yolk sac tumor-derived cell line that is known to express endocytotically active megalin..$^{21,31} \mathrm{~L} 2$ cells were incubated with ${ }^{125} \mathrm{I}-\mathrm{L}-\mathrm{FABP}$ either alone or in the presence of various competitors (Figure 6). Degradation products of ${ }^{125} \mathrm{I}-\mathrm{L}-\mathrm{FABP}$ were detected in the culture media of L2 cells, and the amount of degradation products was significantly reduced in the presence of excess unlabeled L-FABP, suggesting the presence of a specific processing pathway of

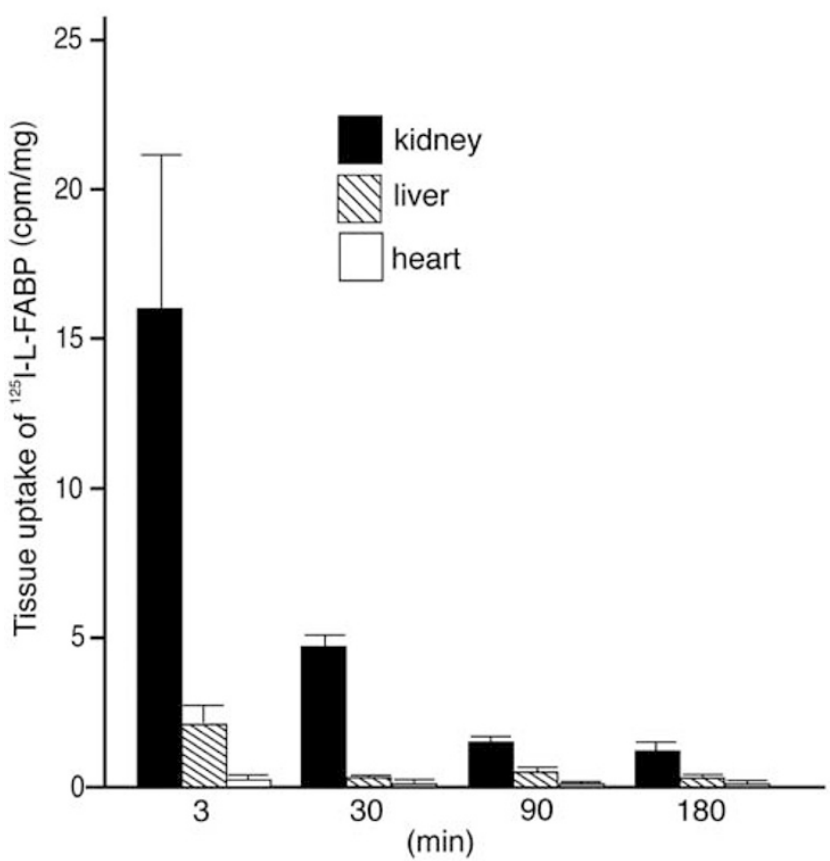

Figure 3 Tissue uptake of circulatory ${ }^{125}$ I-L-FABP. At 3, 30, 90, and $180 \mathrm{~min}$ after intravenous injection of ${ }^{125} \mathrm{I}-\mathrm{L}-\mathrm{FABP}$ into rats, the kidneys, liver, and heart were excised $(n=4) .{ }^{125} \mathrm{I}-\mathrm{L}-\mathrm{FABP}$ accumulated in the kidney immediately after injection. The amount of ${ }^{125}$ I-L-FABP uptake by the kidney was significantly greater than that by the other examined tissues at all time points. The ${ }^{125}$ I-count per weight of tissue (mg) is shown.

L-FABP. To determine whether megalin participates in the processing of ${ }^{125}$ I-L-FABP, additional incubations were performed in the presence of polyclonal antimegalin IgG antibody or a GST-RAP fusion protein. RAP is a protein that is normally found in the endoplasmic reticulum and it binds megalin with high affinity, thereby preventing megalin from associating with other ligands. ${ }^{32}$ Both antimegalin IgG antibody and GST-RAP significantly reduced the level of ${ }^{125}$ I-L-FABP degradation compared with nonimmune IgG and GST, respectively, indicating that megalin participates in the cellular uptake and catabolism of ${ }^{125}$ I-L-FABP by L2 cells, and that it may have a similar function in PTC.

\section{Discussion}

In this study, we found that L-FABP was localized in the lysosomes of PTC on immunohistochemistry and immunoelectron microscopy of the rat kidney. Then, using an acute liver injury rat model in which intrahepatic cell proteins are released into the bloodstream, we showed evidence that L-FABP is transported via the circulation to the kidney. Intravenous administration of radiolabeled L-FABP to rats followed by histoautoradiography of kidney sections revealed that L-FABP is filtered by glomeruli and taken up via the apical membranes of PTC. The QCM analysis demonstrated that megalin, an 

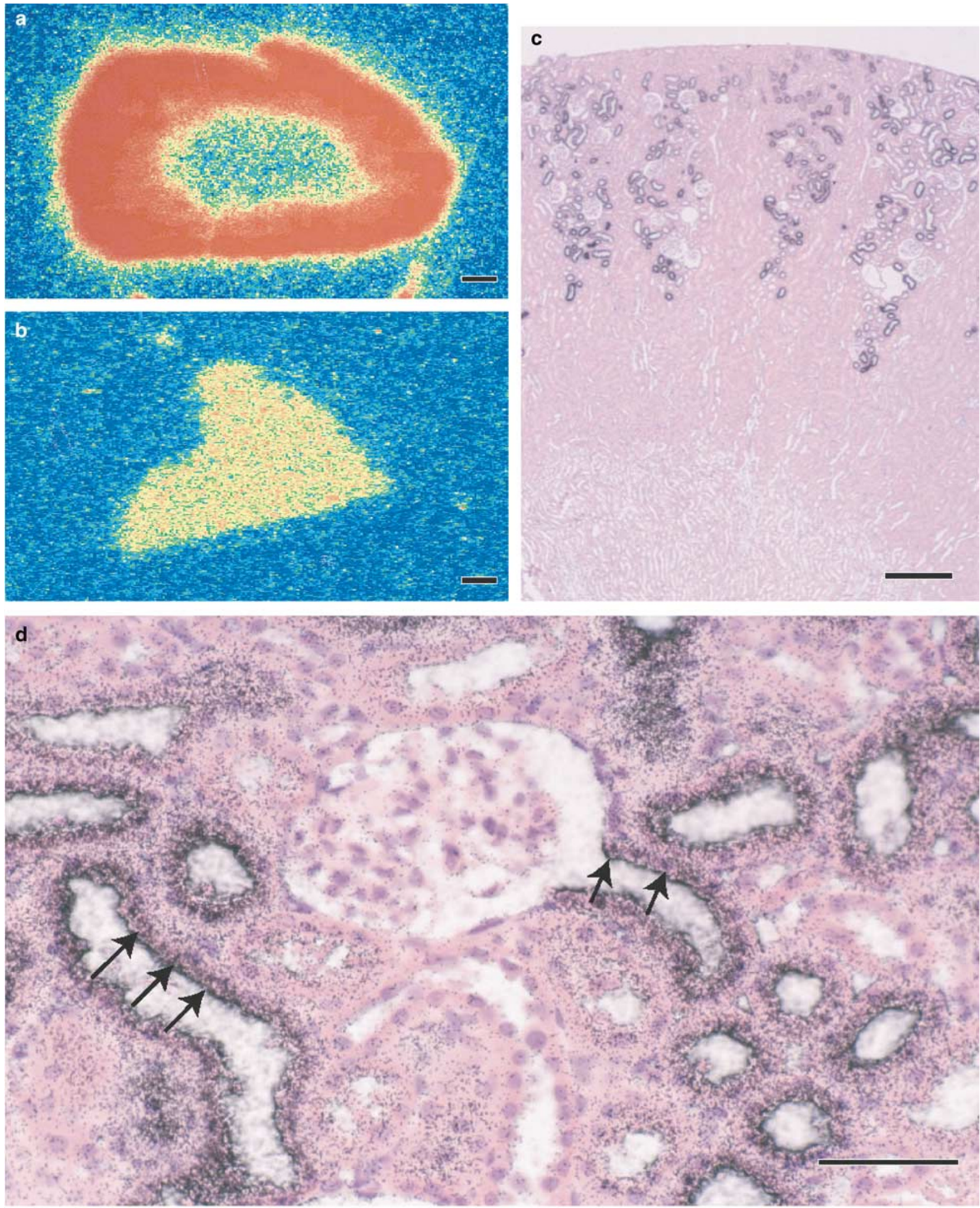

Figure 4 Histoautoradiographs of kidney sections after intravenous injection of ${ }^{35}$ S-L-FABP into rats. (a and b) Imaging plate analyses: At $10 \mathrm{~min}$ after intravenous injection of ${ }^{35} \mathrm{~S}-\mathrm{L}-\mathrm{FABP}$ into rats, the kidneys and liver were excised. Cryosections of the kidneys and liver were placed on a phosphor-imaging plate. The exposed imaging plate was scanned and quantified with an imaging analyzer. High radioactivity was detected in the renal cortex (a), and much less radioactivity was detected in the liver (b). (c and d) Histoautoradiography: Paraffin sections of the kidney were subjected to histoautoradiography and counterstained with hematoxylin and eosin. Silver grains accumulated in the apical membranes of proximal tubules (arrows). Scale bars: $1000 \mu \mathrm{m}$ in (a and b) $500 \mu \mathrm{m}$ in (c) $50 \mu \mathrm{m}$ in (d). 

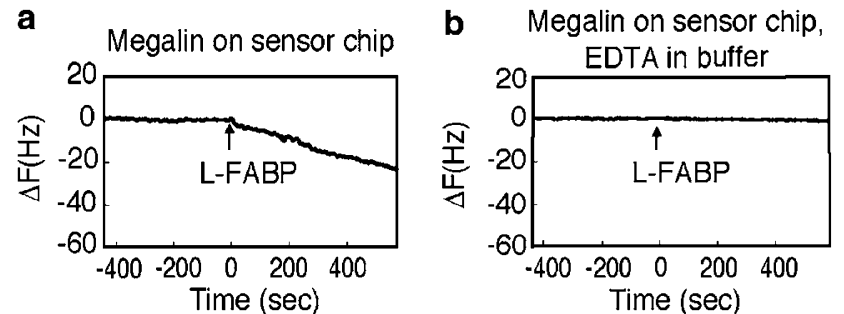

C FA-free BSA on sensor chip
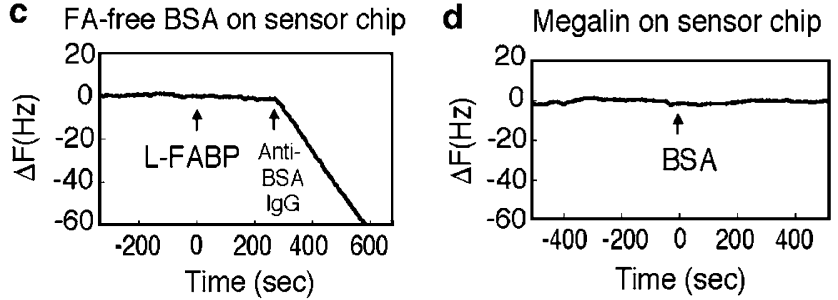

e Megalin on sensor chip,

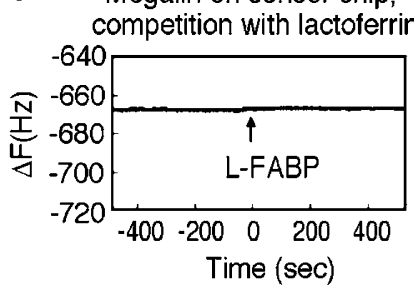

Figure 5 QCM analysis for the binding of L-FABP to megalin. LFABP (a, b, e), BSA (d) or L-FABP and anti-BSA IgG (c) $(1 \mu \mathrm{g} / \mathrm{ml}$, each) were injected at the time points indicated by the arrows into the QCM chamber in which megalin $(\mathbf{a}, \mathbf{b}, \mathbf{d}, \mathbf{e})$ or FA-free BSA (c) had been immobilized on the sensor chips. The buffer in the chamber contained $2 \mathrm{mM} \mathrm{Ca}^{2+}$ in (a), (c)-(e), and $10 \mathrm{mM}$ EDTA in (b). The binding of the injected proteins to the chip-immobilized protein is indicated by a change in the frequency, $\Delta \mathrm{F}$. All the experiments were repeated at least three times and the representative results are shown. (a) L-FABP bound to megalin in the presence of $\mathrm{Ca}^{2+}$. (b) L-FABP did not bind to megalin in the absence of $\mathrm{Ca}^{2+}$, indicating that the binding is $\mathrm{Ca}^{2+}$-dependent. (c) FA-free BSA that was immobilized on the sensor chip, did not bind to L-FABP, but did bind to anti-BSA IgG in the presence of $\mathrm{Ca}^{2+}$. (d) BSA (FA-bound) did not bind to megalin even in the presence of $\mathrm{Ca}^{2+}$. (e) Lactoferrin $(3 \mu \mathrm{g} / \mathrm{ml})$, a ligand for megalin, was initially injected and allowed to reach the steady state of its binding to megalin before the injection of L-FABP. L-FABP did not bind to megalin in this condition even in the presence of $\mathrm{Ca}^{2+}$.

endocytotic receptor on PTC, has L-FABP binding activity that was dependent on the presence of $\mathrm{Ca}^{2+}$. In cultured megalin-expressing L2 cells, megalin mediated the cellular uptake and catabolism of L-FABP. These findings suggest that megalin plays a role in the endocytosis of L-FABP in the kidney.

Megalin is a large $(\sim 600 \mathrm{kDa})$ glycoprotein that belongs to the low-density lipoprotein receptor gene family. ${ }^{19}$ It is found in the clathrin-coated pits of PTC; it internalizes ligands into endocytotic compartments, and it is then recycled to the cell surface. ${ }^{31,33}$ Ligands that are endocytosed via megalin include multiple low-molecular weight proteins such as parathyroid hormone, ${ }^{34}$ insulin, $\beta_{2}$-microglobulin, epidermal growth factor, prolactin, lysozyme, cytochrome $C,^{35} \alpha_{1}$-microglobulin, odorant-binding protein, ${ }^{36}$ transthyretin ${ }^{37}$ and leptin. ${ }^{26}$ The majority of

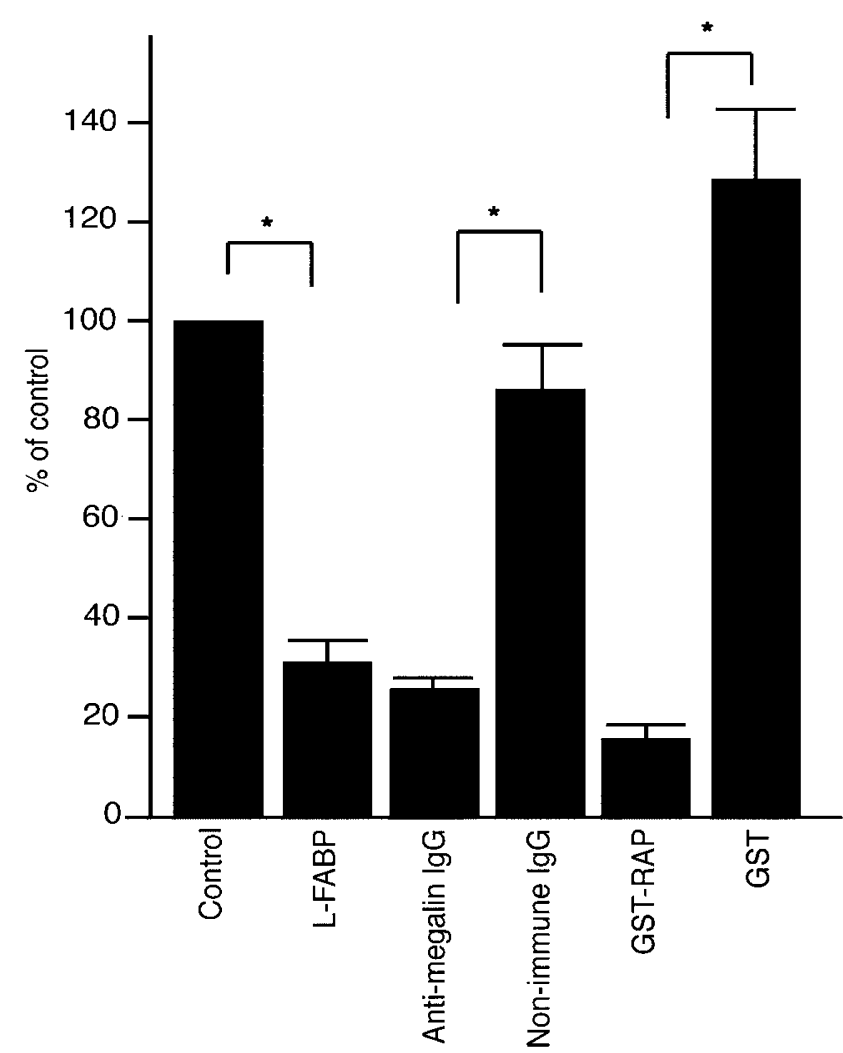

Figure 6 Cellular degradation analysis for endocytosis of ${ }^{125} \mathrm{I}-\mathrm{L}$ FABP. Cultured L2 cells were incubated with ${ }^{125}$ I-L-FABP in DMEM containing $0.1 \%$ BSA for $2 \mathrm{~h}$ for degradation assays in the absence or presence of the indicated competitors. The addition of unlabeled L-FABP $(100 \mu \mathrm{g} / \mathrm{ml})$ reduced the degradation of ${ }^{125} \mathrm{I}-\mathrm{L}$ FABP. Antimegalin IgG antibody $(200 \mu \mathrm{g} / \mathrm{ml})$ and GST-RAP $(100 \mu \mathrm{g} / \mathrm{ml})$ significantly inhibited the degradation compared to non-immune IgG $(200 \mu \mathrm{g} / \mathrm{ml})$ and GST $(100 \mu \mathrm{g} / \mathrm{ml})$, respectively, indicating that megalin mediates the endocytosis of ${ }^{125} \mathrm{I}-\mathrm{L}-\mathrm{FABP}$. Values (means \pm s.d., $n=4$ ) are expressed relative to the control. ${ }^{*} P<0.01$.

the ligands that are internalized by megalin are transported via endocytotic vesicles to lysosomes, resulting in their dissociation and degradation. ${ }^{38}$

Megalin also regulates the endocytosis of complexes of vitamins and carrier proteins such as transcobalamin, ${ }^{39}$ vitamin D-binding protein (DBP) ${ }^{40}$ and retinol-binding protein, ${ }^{41}$ indicating the importance of megalin in both maintaining vitamin homeostasis and metabolizing certain vitamins, notably the renal hydroxylation of vitamin D. ${ }^{42}$ The megalin-mediated uptake of $25-(\mathrm{OH})$ vitamin $\mathrm{D}_{3}$ by PTC is followed by lysosomal degradation of DBP and subsequent conversion of 25- $(\mathrm{OH})$ vitamin $\mathrm{D}_{3}$ to $1,25-(\mathrm{OH})_{2}$ vitamin $\mathrm{D}_{3}$, which is then returned to the circulation. ${ }^{40}$ Megalin, as well as its cooperative receptor cubilin, is also involved in the PTC uptake of Clara cell secretory protein that is translocated from the airway lumen to the circulation and serves as a carrier of steroid hormones and polychlorinated biphenyl metabolites. ${ }^{43}$

FFA are an important energy source in the kidney and are thought to be carried to the kidney mostly by 
albumin, a major FFA-binding protein in the circulation. The results of the current study suggest a novel pathway of renal uptake of FFA via L-FABP, which binds FFA with high affinity. FFA have toxic effects in nephrotic states in which a large amount of FFA is filtered along with albumin by glomeruli and reabsorbed by PTC, causing tubulo-interstitial injury ${ }^{18} \mathrm{~A}$ previous in vitro study demonstrated that L-FABP tends to dissociate FFA ligands at lower $\mathrm{pH},{ }^{44}$ suggesting that L-FABP may dissociate the ligands in endocytotic compartments. Further studies are required to determine whether the FFAcarrying function of L-FABP has physiological significance in the kidney and whether L-FABP modulates the nephrotoxicity induced by the accumulation of FFA in proximal tubules.

L-FABP also binds other hydrophobic molecules such as lysophospholipids, ${ }^{1}$ eicosanoids, ${ }^{3,4}$ bile acids, ${ }^{5}$ bilirubin, ${ }^{6}$ and heme. ${ }^{7}$ It is thus possible that L-FABP in the circulation transports these ligands into PTC via a megalin-mediated uptake pathway. Some patients with liver damage have renal tubular injury which presumably resulted from the direct cytotoxicity of nephrotoxic substances including bilirubin $^{45}$ and bile acids. ${ }^{46}$ Patients with liver damage have a higher serum level of L-FABP than healthy individuals, ${ }^{12}$ and these patients may have increased proximal tubular uptake of L-FABP along with its ligands, as suggested by our finding that rats with $\mathrm{CCl}_{4}$-induced liver injury had increased levels of L-FABP in the serum and kidney, while the level of L-FABP mRNA expression in the kidney was low and did not significantly differ from that in control rats (Figure 2). Since some ligands of L-FABP are nephrotoxic, this may be one potential mechanism of the development of renal injury in patients with liver damage. In addition, L-FABP binds with some carcinogenic agents ${ }^{8}$ and hypolipidemic drugs, ${ }^{9}$ and the uptake of these drugs into PTC via megalinmediated endocytosis may be associated with druginduced nephrotoxicity. Future studies should examine these hypotheses using appropriate experimental models.

In conclusion, the present findings provide evidence that L-FABP, a carrier of FFA and other hydrophobic ligands, is transported through the circulation into PTC by megalin-mediated endocytosis. L-FABP may play a pathological role, especially in the proximal tubular injury seen among patients with liver damage. Further studies are needed to elucidate the roles of L-FABP in the kidney under normal and pathological conditions.

\section{Acknowledgements}

We thank Drs Go Hasegawa and Yasunobu Matsuda for their technical assistance and suggestions. Part of this work was presented at the 36th Annual Meeting of the American Society of Nephrology, San Diego, CA (J Am Soc Nephrol 14: 307A, 2003). We have no duality of interest to declare concerning this study. This work was supported by Grants-in-Aid for Scientific Research from the Ministry of Education, Science, and Culture of Japan (10670989, 14571018 and 15659202).

\section{References}

1 Zimmerman AW, Veerkamp JH. New insights into the structure and function of fatty acid-binding proteins. Cell Mol Life Sci 2002;59:1096-1116.

2 Vancura A, Haldar D. Regulation of mitochondrial and microsomal phospholipid synthesis by liver fatty acidbinding protein. J Biol Chem 1992;267:14353-14359.

3 Dutta-Roy AK, Gopalswamy N, Trulzsch DV. Prostaglandin E1 binds to $\mathrm{Z}$ protein of rat liver. Eur J Biochem 1987;162:615-619.

4 Raza H, Pongubala JR, Sorof S. Specific high affinity binding of lipoxygenase metabolites of arachidonic acid by liver fatty acid binding protein. Biochem Biophys Res Commun 1989;161:448-455.

5 Takikawa H, Kaplowitz N. Binding of bile acids, oleic acid, and organic anions by rat and human hepatic $\mathrm{Z}$ protein. Arch Biochem Biophys 1986;251:385-392.

6 Levi AJ, Gatmaitan Z, Arias IM. Two hepatic cytoplasmic protein fractions, $\mathrm{Y}$ and $\mathrm{Z}$, and their possible role in the hepatic uptake of bilirubin, sulfobromophthalein, and other anions. J Clin Invest 1969;48: 2156-2167.

7 Billheimer JT, Gaylor JL. Cytosolic modulators of activities of microsomal enzyme of cholesterol biosynthesis. Role of a cytosolic protein with properties similar to Z-protein (fatty acid-binding protein). J Biol Chem 1980;255:8128-8135.

8 Khan SH, Sorof S. Preferential binding of growth inhibitory prostaglandins by the target protein of a carcinogen. Proc Natl Acad Sci USA 1990;87: 9401-9405.

9 Wolfrum C, Borrmann CM, Borchers T, et al. Fatty acids and hypolipidemic drugs regulate peroxisome proliferator-activated receptors alpha- and gammamediated gene expression via liver fatty acid binding protein: a signaling path to the nucleus. Proc Natl Acad Sci USA 2001;98:2323-2328.

10 Kanda T, Ono T, Matsubara Y, et al. Possible role of rat fatty acid-binding proteins in the intestine as carriers of phenol and phthalate derivatives. Biochem Biophys Res Commun 1990;168:1053-1058.

11 Takahashi K, Odani S, Ono T. Isolation and characterization of the three fractions (DE-I, DE-II and DE-III) of rat-liver Z-protein and the complete primary structure of DE-II. Eur J Biochem 1983;136:589-601.

12 Pelsers MM, Morovat A, Alexander GJ, et al. Liver fatty acid-binding protein as a sensitive serum marker of acute hepatocellular damage in liver transplant recipients. Clin Chem 2002;48:2055-2057.

13 Maatman RG, Van Kuppevelt TH, Veerkamp JH. Two types of fatty acid-binding protein in human kidney. Isolation, characterization and localization. Biochem J 1991;273(Part 3):759-766.

14 Maatman RG, van de Westerlo EM, van Kuppevelt TH, et al. Molecular identification of the liver- and the heart-type fatty acid-binding proteins in human and rat kidney. Use of the reverse transcriptase polymerase chain reaction. Biochem J 1992;288(Part 1):285-290. 
15 Freeman DM, Chan L, Yahaya H, et al. Magnetic resonance spectroscopy for the determination of renal metabolic rate in vivo. Kidney Int 1986;30:35-42.

16 Hohenleitner FJ, Spitzer JJ. Changes in plasma free fatty acid concentrations on passage through the dog kidney. Am J Physiol 1961;200:1095-1098.

17 Lee JB, Vance VK, Cahill Jr GF. Metabolism of C-14labeled substrates by rabbit kidney cortex and medulla. Am J Physiol 1962;203:27-36.

18 Thomas ME, Schreiner GF. Contribution of proteinuria to progressive renal injury: consequences of tubular uptake of fatty acid bearing albumin. Am J Nephrol 1993;13:385-398.

19 Saito A, Pietromonaco S, Loo AK, et al. Complete cloning and sequencing of rat gp330/'megalin,' a distinctive member of the low density lipoprotein receptor gene family. Proc Natl Acad Sci USA 1994; 91:9725-9729.

20 Hitomi M, Odani S, Ono T. Glutathione-protein mixed disulfide decreases the affinity of rat liver fatty acidbinding protein for unsaturated fatty acid. Eur J Biochem 1990;187:713-719.

21 Lundstrom M, Orlando RA, Saedi MS, et al. Immunocytochemical and biochemical characterization of the Heymann nephritis antigenic complex in rat L2 yolk sac cells. Am J Pathol 1993;143:1423-1435.

22 Uchida T, Endo T. Immunoelectron microscopic demonstration of $\mathrm{S}-100 \mathrm{~b}$ protein-like in centriole, cilia, and basal body. J Histochem Cytochem 1988;36: 693-696.

23 Recknagel RO. Carbon tetrachloride hepatotoxicity. Pharmacol Rev 1967;19:145-208.

24 Noguchi T, Matsuyama S, Akao M, et al. Induction of hepatic tissue-type plasminogen activator and type 1 plasminogen activator-inhibitor gene expressions and appearance of their translation products in the bile following acute liver injury in rats. Thromb Res 2001;104:283-291.

25 Gordon JI, Alpers DH, Ockner RK, et al. The nucleotide sequence of rat liver fatty acid binding protein mRNA. J Biol Chem 1983;258:3356-3363.

26 Hama H, Saito A, Takeda T, et al. Evidence indicating that renal tubular metabolism of leptin is mediated by megalin but not by the leptin receptors. Endocrinology 2004;145:3935-3940.

27 Abbate M, Bachinsky D, Zheng G, et al. Location of gp330/alpha 2-m receptor-associated protein (alpha 2-MRAP) and its binding sites in kidney: distribution of endogenous alpha 2-MRAP is modified by tissue processing. Eur J Cell Biol 1993;61:139-149.

28 Willnow TE, Goldstein JL, Orth K, et al. Low density lipoprotein receptor-related protein and gp330 bind similar ligands, including plasminogen activatorinhibitor complexes and lactoferrin, an inhibitor of chylomicron remnant clearance. J Biol Chem 1992;267: 26172-26180.

29 Wewer U. Characterization of a rat yolk sac carcinoma cell line. Dev Biol 1982;93:416-421.
30 Orlando RA, Farquhar MG. Functional domains of the receptor-associated protein (RAP). Proc Natl Acad Sci USA 1994;91:3161-3165.

31 Czekay RP, Orlando RA, Woodward L, et al. Endocytic trafficking of megalin/RAP complexes: dissociation of the complexes in late endosomes. Mol Biol Cell 1997; 8:517-532.

32 Orlando RA, Kerjaschki D, Kurihara H, et al. gp330 associates with a $44-\mathrm{kDa}$ protein in the rat kidney to form the Heymann nephritis antigenic complex. Proc Natl Acad Sci USA 1992;89:6698-6702.

33 Farquhar MG, Saito A, Kerjaschki D, et al. The Heymann nephritis antigenic complex: megalin (gp330) and RAP. J Am Soc Nephrol 1995;6:35-47.

34 Hilpert J, Nykjaer A, Jacobsen C, et al. Megalin antagonizes activation of the parathyroid hormone receptor. J Biol Chem 1999;274:5620-5625.

35 Orlando RA, Rader K, Authier F, et al. Megalin is an endocytic receptor for insulin. J Am Soc Nephrol 1998; 9:1759-1766.

36 Leheste JR, Rolinski B, Vorum H, et al. Megalin knockout mice as an animal model of low molecular weight proteinuria. Am J Pathol 1999;155: 1361-1370.

37 Sousa MM, Norden AG, Jacobsen C, et al. Evidence for the role of megalin in renal uptake of transthyretin. J Biol Chem 2000;275:38176-38181.

38 Willnow TE, Nykjaer A, Herz J. Lipoprotein receptors: new roles for ancient proteins. Nat Cell Biol 1999;1: E157-E162.

39 Moestrup SK, Birn H, Fischer PB, et al. Megalinmediated endocytosis of transcobalamin-vitamin-B12 complexes suggests a role of the receptor in vitaminB12 homeostasis. Proc Natl Acad Sci USA 1996;93: 8612-8617.

40 Nykjaer A, Dragun D, Walther D, et al. An endocytic pathway essential for renal uptake and activation of the steroid 25-(OH) vitamin D3. Cell 1999;96:507-515.

41 Christensen EI, Moskaug JO, Vorum H, et al. Evidence for an essential role of megalin in transepithelial transport of retinol. J Am Soc Nephrol 1999;10: 685-695.

42 Christensen EI, Birn H. Megalin and cubilin: synergistic endocytic receptors in renal proximal tubule. Am J Physiol Renal Physiol 2001;280:F562-F573.

43 Burmeister R, Boe IM, Nykjaer A, et al. A two-receptor pathway for catabolism of Clara cell secretory protein in the kidney. J Biol Chem 2001;276:13295-13301.

$44 \mathrm{Kim}$ HK, Storch J. Free fatty acid transfer from rat liver fatty acid-binding protein to phospholipid vesicles. Effect of ligand and solution properties. J Biol Chem 1992;267:77-82.

45 Rector Jr WG, Kanel GC, Rakela J, et al. Tubular dysfunction in the deeply jaundiced patient with hepatorenal syndrome. Hepatology 1985;5:321-326.

46 Bairaktari E, Liamis G, Tsolas O, et al. Partially reversible renal tubular damage in patients with obstructive jaundice. Hepatology 2001;33:1365-1369. 